\title{
Evaluation of Grapevines for Resistance to Downy Mildew (Plasmopara viticola) under Laboratory and Field Conditions
}

\author{
T. Prajongjai, O. Poolsawat, P. Pornbungkerd, S. Wongkaew, P.A. Tantasawat*
}

Suranaree University of Technology, 111 University Avenue, Muang District, Nakhon Ratchasima 30000, Thailand

Submitted for publication: July 2013

Accepted for publication: November 2013

Key words: Correlation, disease resistance, disease screening method, grape, hybrid, propagation method, Vitis spp.

\begin{abstract}
Downy mildew of grapevine (Vitis vinifera L.), caused by the oomycete Plasmopara viticola, can seriously devastate grapevine production in tropical countries, such as Thailand. Four susceptible grapevine cultivars, four potentially resistant lines and $18 \mathrm{~F}_{1}$ hybrids, propagated by air layering and chip budding, were evaluated for resistance to downy mildew at laboratory (using a detached leaf assay) and field (natural infection in 2011 and 2013) levels. Significant differences in the disease scores among grapevine genotypes, ranging from 0.54 (resistant) to 4.83 (susceptible) and 3.30 (resistant) to 7.70 (susceptible), were observed under the laboratory and field conditions respectively. No significant difference in disease severity was observed between the two propagation methods or between the two different years of field evaluations. Resistance evaluations under both conditions consistently classified 'NY88.0517.01' and 'NY65.0550.04' as resistant lines what would be useful as parents for future breeding programmes. Moreover, one $\mathrm{F}_{1}$ hybrid, 'SUT0403.09', was reported to have considerable resistance to downy mildew under both laboratory and field conditions for the first time. The field resistance level of this hybrid was almost comparable to its highly resistant parent 'Wilcox 321', suggesting its potential for the future development of resistant cultivars in Thailand. Although the ranking of genotypes varied between screening methods, the resistance levels of the 26 grapevine genotypes evaluated under laboratory and field conditions were comparable based on the Spearman's rank correlation coefficients of $0.73(p \leq 0.01)$. These results suggest that the laboratory screening assay is efficient for the rapid, reliable and economical identification of resistant hybrids in grapevine breeding programmes.
\end{abstract}

\section{INTRODUCTION}

Grapevine is a high-value fruit crop that can be grown in several regions of Thailand. However, its cultivation has been limited by the high costs associated with intensive pest management. Most cultivars grown in Thailand are Vitis vinifera L., which produces high-quality grapes, but it is susceptible to several diseases, including downy mildew. Therefore, grapevine production is usually negatively influenced by destructive diseases throughout the year. Downy mildew, caused by the oomycete Plasmopora vitocola, is one of the major grapevine diseases in Thailand. In the growing season, the disease infects all green shoot tissues, including leaves, tendrils, shoots, inflorescences and fruit bunches (Lafon \& Clerjeau, 1988). Symptoms appear as yellowish, oily spots on the bottom of the leaves, followed by the development of white sporangiophores and sporangia on the abaxial leaf surface under warm, humid conditions. The disease can rapidly affect whole grapevines, resulting in 50 to $75 \%$ of crop losses in one season. Moreover, the quality may decline since only 25 to $50 \%$ of the sugar remains in the infected berries (Agrios, 1997; CAB International, 2000).

The most commonly employed method for controlling grape downy mildew is the application of preventative and curative fungicides. However, the use of chemical fungicides not only increases grapevine production costs, but also has an adverse impact on the environment and could possibly have a negative effect on consumer health (Gessler et al., 2011). It has been reported that grafting or chip budding on rootstocks is useful for resistance to some biotic stresses such as phylloxera (Schmid et al., 1998), root nematode (McCarthy \& Cirami, 1990) and crown gall (Diana \& Dejeu, 2011). In addition, rootstocks may promote enhanced adaptability to abiotic stresses such as high or low soil pH (Bavaresco et al., 1992), wet or poorly drained soils (Striegler et al., 1993), and drought (Pavloušek, 2011). Numerous reports have also proved that rootstocks affect vine growth, yield, fruit quality and wine quality (Reynolds \& Wardle, 2001; Satisha et al., 2010; Nilnond et al., 2011). However, whether propagation by chip budding on rootstocks has beneficial effects on

*Corresponding author: e-mail address: piyada@sut.ac.th

Aknowledgements: The authors are very grateful to Dr Bruce I. Reisch, for providing resistant line cuttings and advice. This research is partially supported by the Higher Education Research Promotion and National Research University Project of Thailand, Office of the Higher Education Commission, Ministry of Education, and grants from Suranaree University of Technology and National Science and Technology Development Agency, Thailand. The authors also thank Mr Peter Bint, for editing the manuscript 
resistance to foliar diseases such as downy mildew when compared to own-root propagation (e.g. cutting, air layering) has not been investigated.

The cultivation of cultivars showing durable resistance to downy mildew is considered as being the most effective and economical strategy for controlling the disease (Pavloušek, 2012). Thus, conventional breeding for downy mildew resistance has frequently been employed, using Muscadinia species, American and Asian cultivars or wild species, as a source to introgress resistance into a $V$. vinifera background (Reisch \& Pratt, 1996; Mahanil, 2007; Sotolář, 2007; Yun et al., 2008; Zamboni et al., 2009). In Thailand, where the disease pressure is high, resistant cultivars are particularly desirable. Therefore, our grapevine breeding programme at the Suranaree University of Technology (SUT) aims to develop new disease-resistant varieties by combining the resistance characteristics of introduced American hybrids with the high fruit quality of $V$. vinifera cultivars grown in Thailand (e.g. 'Black Queen', 'Calorina Black Rose', 'Italia' and 'Early Muscat'). Some of these resulting hybrids were shown to be resistant to anthracnose (Poolsawat et al., 2012), but the resistance levels of these hybrids to downy mildew have not been reported.

Resistance to downy mildew can be evaluated using field evaluations, greenhouse-based screening methods or laboratory-based techniques, i.e. leaf disc, detached leaf, single-node cutting and in vitro dual culture methods (Barlass et al., 1986; Staudt \& Kassemeyer, 1995; Brown et al., 1999; Liu et al., 2003; Boso et al., 2006; Mahanil, 2007; Sotolář, 2007; Boso et al., 2011). In field evaluations, the genotypic effect can be confounded by environmental and other biotic effects, necessitating multi-environment testing. This will prolong the field evaluation process for resistance to downy mildew epidemics, which most often develop during the winter season in Thailand, especially in perennial crops like grapevine. The need for a specific environment for disease development and the high variability of the disease across fields further complicate field evaluations. In addition, if environmental conditions conducive to disease development do not occur, field evaluation may be unreliable (Nelson et al., 1991). Therefore, this approach is frequently considered to be time-consuming, laborious, costly and inefficient for the large-scale screening of grapevines (Brown et al., 1999; Sotolár, 2007). The development of a reliable, controlledenvironment resistance screening method that can accurately predict field resistance is a prerequisite to ensure successful grapevine breeding programmes. It has been reported that laboratory screenings are capable of screening large numbers of breeding progenies rapidly, and are particularly valuable for resistance screening where natural vineyard infection occurs sporadically and infrequently (Brown et al., 1999). Comparisons between laboratory, greenhouse and field screenings suggest that the leaf disc technique appears to be a good predictor of field resistance to downy mildew, and that it is more practical than the greenhouse method for screening large populations (Brown et al., 1999). However, Stein et al. (1985) found that the correlation between the development of downy mildew on leaf discs and on vines in the field and greenhouse was not as highly correlated as for powdery mildew. The detached whole leaf method is another laboratory method that can be used for resistance screenings. Boso et al. (2006) found that this method correlated well with the leaf disc method and the whole plant greenhouse method. However, they did not compare these methods to resistance under field conditions.

The objectives of this study were: 1) to evaluate the effectiveness of a laboratory screening assay in predicting the field responses of grapevines to $P$. viticola; 2 ) to investigate the influence of propagation methods on the levels of downy mildew resistance among parents and $F_{1}$ hybrids of nine crosses under both laboratory and field evaluations; and 3) to identify grapevine genotypes resistant to downy mildew. This knowledge will be beneficial for the breeding of grapevines to improve downy mildew resistance in the future.

\section{MATERIALS AND METHODS \\ Plant materials}

Twenty-six grapevine genotypes with varying resistance levels to $P$. viticola were used for laboratory and field evaluations of downy mildew resistance, and consisted of (i) four potentially resistant lines (male parents): 'Wilcox 321', 'NY88.0517.01', 'NY65.0550.04' and 'NY65.0551.05', (ii) four susceptible cultivars with high fruit quality (female parents): 'Black Queen', 'Carolina Black Rose', 'Italia' and 'Early Muscat', and (iii) eighteen $\mathrm{F}_{1}$ hybrids from nine crosses (Table 1). The potentially resistant lines that are complex interspecific hybrids, 'NY88.0517.01' (Joannes Seyve $23.416 \times($ V rupestris $\times$ V. cinerea $))$, 'NY65.0550.04' [(Jaeger $70($ V. rupestris $\times V$. lincecumii $) \times$ Victoria's Choice $)$ $\times$ (Seyve Villard 23-18 selfed)], 'NY65.0551.05' [(Jaeger 70 $(V$. rupestris $\times V$. lincecumii $) \times$ Victoria's Choice $) \times$ Lady Patricia (S.14664 × S.V. 20-365)], and 'Wilcox 321' [Blue Jay $(V$. riparia $\times V$. labrusca $) \times \mathrm{MN} 242]$, were obtained from the grape breeding programme at New York State Agricultural Experiment Station (NYSAES), Cornell University, Geneva, New York, USA. These genotypes had variable levels of genetic composition from several American species, such as $V$. cinerea, $V$. riparia, $V$. rupestris, $V$. labrusca and $V$. lincecumii, along with $V$. vinifera in their pedigrees. In total, eight parents and eighteen hybrids were propagated by air layering (own root) and chip budding on a rootstock cv. 'Courderc1613', and planted at SUT Farm, Nakhon Ratchasima, Thailand in May 2008 in a randomised complete block design (RCBD) with five one-plant replications using $2 \times 2 \mathrm{~m}$ spacing.

\section{Laboratory evaluation}

Downy mildew resistance was evaluated at the laboratory level using a detached leaf assay as described by Mahanil (2007). Leaves of similar age and size (leaves at nodes 5 to 7, counted from the top) of field-grown plants at SUT Farm were selected and incubated in the dark for $1 \mathrm{~d}$. The leaves were surface-disinfected with $0.09 \%(\mathrm{w} / \mathrm{v})$ sodium hypochlorite and $0.01 \%(\mathrm{v} / \mathrm{v})$ Tween 20 , rinsed three times with sterile distilled water, and placed abaxial surface up on moist filter paper over water agar (WA; 1\%, w/v, agar) in a Petri dish. Five replicates (three leaves/replicate) were inoculated for each grapevine genotype. Sporangia of $P$. viticola were collected from downy mildew-infected $V$. vinifera leaves that were harvested from the field at 
TABLE 1

Disease severity of Plasmopara viticola in a laboratory evaluation using a detached leaf assay of eight grapevine genotypes and $18 \mathrm{~F}_{1}$ hybrids.

\begin{tabular}{|c|c|c|c|c|c|}
\hline \multirow[t]{2}{*}{ Genotypes } & \multirow[b]{2}{*}{ Sources } & \multicolumn{2}{|c|}{ Disease scores $^{1}$} & \multirow{2}{*}{$\begin{array}{c}\text { Mean } \\
\text { disease } \\
\text { scores }^{2}\end{array}$} & \multirow{2}{*}{$\begin{array}{l}\text { Resistance } \\
\text { levels }^{3}\end{array}$} \\
\hline & & $\begin{array}{c}\text { Air } \\
\text { layering }\end{array}$ & $\begin{array}{c}\text { Chip } \\
\text { budding }\end{array}$ & & \\
\hline Black Queen & V. vinifera & 4.87 & 4.80 & $4.83 \mathrm{a}$ & $\mathrm{S}$ \\
\hline Carolina Black Rose & $V$. vinifera & 4.60 & 4.37 & $4.49 \mathrm{ab}$ & $\mathrm{S}$ \\
\hline Early Muscat & $V$. vinifera & 4.47 & 4.40 & $4.43 \mathrm{ab}$ & $\mathrm{S}$ \\
\hline Italia & $V$. vinifera & 4.60 & 4.60 & $4.60 \mathrm{a}$ & $\mathrm{S}$ \\
\hline Wilcox 321 & Blue Jay $\times$ MN $242($ MN 11× Diamond $)$ & 3.07 & 2.96 & $3.01 \mathrm{ef}$ & M \\
\hline NY88.0517.01 & Joannes Seyve $23.416 \times(V$. rupestris $\times V$. cinerea $)$ & 0.60 & 0.55 & $0.58 \mathrm{i}$ & $\mathrm{R}$ \\
\hline NY65.0550.04 & $\begin{array}{l}(\text { Jaeger } 70(\text { V. rupestris } \times V \text {. lincecumii }) \times \text { Victoria's } \\
\text { Choice }) \times(\text { Seyve Villard } 23-18 \text { selfed })\end{array}$ & 0.87 & 0.80 & $0.83 \mathrm{i}$ & $\mathrm{R}$ \\
\hline NY65.0551.05 & $\begin{array}{l}(\text { Jaeger } 70(\text { V. rupestris } \times V \text {. lincecumii }) \times \text { Victoria's } \\
\text { Choice }) \times \text { Lady Patricia }(\text { S. } 14664 \times \text { S.V. } 20-365)\end{array}$ & 0.57 & 0.52 & $0.54 \mathrm{i}$ & $\mathrm{R}$ \\
\hline SUT0401.15 & Black Queen $\times$ NY88.0517.01 & 3.33 & 3.13 & $3.23 \mathrm{de}$ & $\mathrm{S}$ \\
\hline SUT0401.32 & Black Queen $\times$ NY88.0517.01 & 0.73 & 1.00 & $0.87 \mathrm{i}$ & $\mathrm{R}$ \\
\hline SUT0401.33 & Black Queen $\times$ NY88.0517.01 & 0.60 & 0.80 & $0.70 \mathrm{i}$ & $\mathrm{R}$ \\
\hline SUT0410.20 & Black Queen $\times$ NY65.0551.05 & 2.87 & 2.40 & $2.63 \mathrm{fg}$ & M \\
\hline SUT0410.31 & Black Queen $\times$ NY65.0551.05 & 3.73 & 3.73 & $3.73 \mathrm{~cd}$ & $\mathrm{~S}$ \\
\hline SUT0403.09 & Carolina Black Rose $\times$ Wilcox 321 & 0.60 & 0.80 & $0.70 \mathrm{i}$ & $\mathrm{R}$ \\
\hline SUT0404.08 & Carolina Black Rose $\times$ NY88.0517.01 & 0.87 & 1.13 & $1.00 \mathrm{i}$ & M \\
\hline SUT0404.11 & Carolina Black Rose $\times$ NY88.0517.01 & 0.80 & 1.17 & $0.98 \mathrm{i}$ & M \\
\hline SUT0405.02 & Carolina Black Rose $\times$ NY65.0550.04 & 1.21 & 1.00 & $1.10 \mathrm{hi}$ & M \\
\hline SUT0405.17 & Carolina Black Rose $\times$ NY65.0550.04 & 3.18 & 3.40 & $3.29 \mathrm{de}$ & $\mathrm{S}$ \\
\hline SUT0406.01 & Carolina Black Rose $\times$ NY65.0551.05 & 4.07 & 4.47 & $4.27 \mathrm{abc}$ & $\mathrm{S}$ \\
\hline SUT0406.09 & Carolina Black Rose $\times$ NY65.0551.05 & 4.33 & 4.47 & $4.40 \mathrm{ab}$ & $\mathrm{S}$ \\
\hline SUT0406.20 & Carolina Black Rose $\times$ NY65.0551.05 & 4.20 & 4.40 & $4.30 \mathrm{abd}$ & $\mathrm{S}$ \\
\hline SUT0412.01 & Early Muscat × NY65.0551.05 & 4.20 & 3.60 & $3.90 \mathrm{bc}$ & $\mathrm{S}$ \\
\hline SUT0412.05 & Early Muscat $\times$ NY65.0551.05 & 2.40 & 2.07 & $2.24 \mathrm{~g}$ & M \\
\hline SUT0412.16 & Early Muscat $\times$ NY65.0551.05 & 2.07 & 2.60 & $2.33 \mathrm{~g}$ & M \\
\hline SUT0407.06 & Italia $\times$ NY88.0517.01 & 2.27 & 2.20 & $2.23 \mathrm{~g}$ & M \\
\hline SUT0409.03 & Italia $\times$ NY65.0551.05 & 1.60 & 1.59 & $1.60 \mathrm{~h}$ & M \\
\hline
\end{tabular}

${ }^{1}$ Combined data from two independent experiments with five replicates. Disease scores were based on spore production per 25 $\mathrm{cm}^{2}$ leaf area: $0=0$ to 5 spores $/ 25 \mathrm{~cm}^{2} ; 1=6$ to 10 spores $/ 25 \mathrm{~cm}^{2} ; 2=11$ to 15 spores $/ 25 \mathrm{~cm}^{2} ; 3=16$ to 25 spores $/ 25 \mathrm{~cm}^{2} ; 4=26$ to 40 spores $/ 25 \mathrm{~cm}^{2}$; and $5=>40$ spores $/ 25 \mathrm{~cm}^{2}$.

${ }^{2}$ Data followed by the same letter in each column do not differ significantly $(p \leq 0.05)$ according to Duncan's multiple range test. ${ }^{3}$ Downy mildew resistance level based on lesion/disease severity scores as follows: 0 to $0.9=$ resistant $(\mathrm{R}), 1.0$ to $3.0=$ moderately resistant (M) and 3.1 to $5.0=$ susceptible $(\mathrm{S})$.

SUT Farm, Nakhon Ratchasima, Thailand from October to December 2010 and incubated in the dark for $8 \mathrm{~h}$. The spore concentration of the collected sporangial suspension was estimated using a haemocytometer and adjusted to $1 \times 10^{5}$ spores $/ \mathrm{mL}$. The sporangial suspensions were sprayed onto the abaxial leaf surface of each leaf until evenly wet. Petri dishes were held at $22^{\circ} \mathrm{C}, 16 \mathrm{~h}$ photoperiod for $8 \mathrm{~d}$. Infected leaves were placed in $5 \mathrm{~mL}$ of double distilled water in a 50 $\mathrm{mL}$ tube and then shaken with a vortex mixer for $3 \mathrm{~min}$. The total number of spores produced per leaf was determined by counting the number of spores in $5 \mu \mathrm{L}$ twice under a microscope. The leaf areas were measured using a leaf area meter. The number of total spores per leaf was converted to number of spores $/ 25 \mathrm{~cm}^{2}$ leaf area, following a formula: number of spores $/ 25 \mathrm{~cm}^{2}$ leaf area $=$ (number of spores $\times$ $25 \mathrm{~cm}^{2}$ leaf area)/actual leaf area $\left(\mathrm{cm}^{2}\right)$. Resistance levels were based on average spore production from two sets of experiments. Disease severity was classified into six classes based on spore production: $0=0$ to 5 spores $/ 25 \mathrm{~cm}^{2} ; 1=6$ to 10 spores $/ 25 \mathrm{~cm}^{2} ; 2=11$ to 15 spores $/ 25 \mathrm{~cm}^{2} ; 3=16$ to 25 spores $/ 25 \mathrm{~cm}^{2} ; 4=26$ to 40 spores $/ 25 \mathrm{~cm}^{2}$; and $5=>40$ spores $/ 25 \mathrm{~cm}^{2}$. Under the laboratory evaluation, resistance/ 
susceptibility levels of grapevine genotypes were classified as resistant (scores of 0 to 0.9 ), moderately resistant (scores of 1.0 to 3.0), and susceptible (scores of 3.1 to 5.0 ).

\section{Field evaluation}

In the winters of 2011 and 2013, when disease intensity was high, downy mildew assessments were conducted at SUT Farm, Nakhon Ratchasima, Thailand. Chemical sprays were withheld during the winter to allow natural infection. The trial layout was an RCBD with five replicates of each grapevine genotype. Disease severity was rated based on the three most heavily infected leaves, which typically were within $0.8 \mathrm{~m}$ of the ground (modified from Cadle-Davidson, 2008), and classified into 10 classes, 1 to 10 , based on the estimated percentage of infected leaf area: $1=$ no visible disease symptom; $2=1$ to $10 \%$ of the leaf area covered by lesions; $3=11$ to $20 \%$ of the leaf area covered by lesions; $4=21$ to $30 \%$ of the leaf area covered by lesions; $5=31$ to $40 \%$ of the leaf area covered by lesions; $6=41$ to $50 \%$ of the leaf area covered by lesions; $7=51$ to $60 \%$ of the leaf area covered by lesions; $8=61$ to $70 \%$ of the leaf area covered by lesions; $9=71$ to $80 \%$ of the leaf area covered by lesions; and $10=>80 \%$ of the leaf area covered by lesions from downy mildew infection. The resistance/susceptibility levels of grapevine genotypes were classified as follows: 1.0 to $1.9=$ highly resistant, 2.0 to $3.9=$ resistant, 4.0 to $6.5=$ moderately resistant, 6.6 to $9.0=$ susceptible, 9.1 to 10 = highly susceptible. Disease severity was evaluated in February 2011 and 2013 when the rainfall was 141.9 and $174.3 \mathrm{~mm}$ respectively. Phenotypic coefficient of variation (PCV), genotypic coefficient of variation (GCV) and broad sense heritability $\left(\mathrm{h}^{2}{ }_{\mathrm{b}}\right)$ were estimated according to Dabholkar (1992) and Okelola et al. (2007).

\section{Statistical analysis}

Disease severity scores from the laboratory and field evaluations were transformed with the formula $(\mathrm{X}+1)^{1 / 2}$ and analysed using analysis of variance (ANOVA) with SPSS version 14.0 (Levesque and SPSS Inc., 2006). The relationships between laboratory (detached leaf) and field (natural infection) evaluations were analysed using Spearman's rank correlation (Spearman, 1904).

\section{RESULTS AND DISCUSSION}

\section{Laboratory evaluation of downy mildew resistance}

In the laboratory evaluation, visible disease symptoms started to appear by the third day after inoculation, but the number of spores on each leaf was recorded at $8 \mathrm{~d}$ after inoculation, when most of the susceptible cultivars were covered by white sporangiophores. Highly significant effects of grapevine genotypes $(p<0.01)$ on disease severity were observed. The average disease scores were significantly different among grapevine genotypes, varying from 0.54 (resistant) in 'NY65.0551.05' to 4.83 (susceptible) in 'Black Queen'. All susceptible cultivars ('Black Queen', 'Carolina Black Rose', 'Early Muscat' and 'Italia') had high disease scores, whereas 'NY88.0517.01', 'NY65.0550.04' and 'NY65.0551.05' were resistant to the disease, and 'Wilcox 321' was moderately resistant. The eighteen hybrids segregated for downy mildew resistance levels within the range of their parents (Table 1). Most of the $F_{1}$ hybrids were moderately resistant $(44.4 \%)$ or susceptible (38.9\%) to downy mildew. But three hybrids, 'SUT0403.09', 'SUT0401.32' and 'SUT0401.33' were resistant (Table 1). In contrast to genotypes, propagation methods did not influence the disease responses $(p>0.05)$, since the disease scores of grapevines propagated by air layering and chip budding were not significantly different (Table 2). Similarly, interactions between grapevine genotypes and propagation methods were not significant $(p>0.05)$.

\section{Field evaluation of downy mildew resistance}

In the field evaluation, average disease severity scores varied significantly $(p<0.01)$ among different genotypes of grapevines. There were no significant differences $(p>0.05)$ in average disease severity scores for the two propagation methods (air layering and chip budding), or between the two years of evaluation (2011 and 2013) at SUT Farm. The disease severity scores ranged from 3.3 (resistant) in 'Wilcox 321 ' to 7.7 (susceptible) in 'Black Queen'. All of the hybrids had lower disease scores than their female $V$. vinifera parents, and most $(88.9 \%)$ were classified as moderately resistant (Table 3). Similar to the laboratory screening, no effect of propagation methods on disease response was observed (Table 2). When disease severity scores for different years were compared, it was found that most genotypes exhibited consistent disease responses for these two years (Table 3), showing the reproducibility of downy mildew resistance found in this study. When disease severity scores from the field evaluations were used for the estimation of PCV, GCV and $\mathrm{h}_{\mathrm{b}}^{2}$, marginal differences were found between PCV and GCV, suggesting a minimal role of the environment on expression of downy mildew resistance. This led to relatively high broad-sense heritability of downy mildew resistance in both years (76.6 and $79.7 \%$ respectively; Table 4 ). This is in agreement with the high narrow-sense heritability of downy mildew resistance $(55.6 \%)$ estimated from gene action analysis (Poolsawat et al., 2013).

\section{Correlations between laboratory and field evaluations of downy mildew resistance}

Because the mean square errors between the field evaluations in 2011 and 2013 were homogeneous, and because of the non-significant difference observed over the two years, field

TABLE 2

Influence of propagation methods on disease severity scores of grapevines in laboratory and field evaluations.

\begin{tabular}{lcccc}
\hline Propagation methods & Laboratory evaluation & \multicolumn{3}{c}{ Field evaluation } \\
\cline { 3 - 5 } & & 2011 & 2013 & Mean \\
\hline Air layering & 2.57 & 5.47 & 5.48 & 5.475 \\
Chip budding & 2.56 & 5.62 & 5.63 & 5.625 \\
\hline
\end{tabular}


TABLE 3

Disease severity of Plasmopara viticola in field evaluations for two years (2011 and 2013) of eight grapevine genotypes and $18 \mathrm{~F}_{1}$ hybrids.

\begin{tabular}{|c|c|c|c|c|}
\hline \multirow[t]{2}{*}{ Genotypes } & \multicolumn{2}{|c|}{ Disease scores for the 2011 and 2013 season $^{1}$} & \multirow[t]{2}{*}{ Mean disease scores ${ }^{2}$} & \multirow[t]{2}{*}{ Resistance levels $^{3}$} \\
\hline & 2011 & 2013 & & \\
\hline Black Queen & 7.50 & 7.90 & $7.70 \mathrm{a}^{1}$ & $\mathrm{~S}^{2}$ \\
\hline Carolina Black Rose & 7.50 & 7.50 & $7.50 \mathrm{a}$ & $\mathrm{S}$ \\
\hline Early Muscat & 6.70 & 6.90 & $6.80 \mathrm{bc}$ & $\mathrm{S}$ \\
\hline Italia & 6.80 & 7.10 & $6.95 \mathrm{~b}$ & $\mathrm{~S}$ \\
\hline Wilcox 321 & 3.30 & 3.30 & $3.30 \mathrm{k}$ & $\mathrm{R}$ \\
\hline NY88.0517.01 & 3.50 & 3.30 & $3.40 \mathrm{k}$ & $\mathrm{R}$ \\
\hline NY65.0550.04 & 3.80 & 3.50 & $3.65 \mathrm{k}$ & $\mathrm{R}$ \\
\hline NY65.0551.05 & 5.70 & 5.50 & $5.60 \mathrm{f}-\mathrm{j}$ & M \\
\hline SUT0401.15 & 5.50 & 5.60 & $5.55 \mathrm{~g}-\mathrm{j}$ & M \\
\hline SUT0401.32 & 5.30 & 5.40 & $5.35 \mathrm{ij}$ & M \\
\hline SUT0401.33 & 5.20 & 4.90 & $5.05 \mathrm{j}$ & M \\
\hline SUT0410.20 & 6.00 & 6.00 & $6.00 \mathrm{e}-\mathrm{h}$ & M \\
\hline SUT0410.31 & 6.70 & 6.70 & $6.70 \mathrm{bcd}$ & $\mathrm{S}$ \\
\hline SUT0403.09 & 3.30 & 3.50 & $3.40 \mathrm{j}$ & $\mathrm{R}$ \\
\hline SUT0404.08 & 5.10 & 5.30 & $5.20 \mathrm{ij}$ & M \\
\hline SUT0404.11 & 5.40 & 5.30 & $5.35 \mathrm{ij}$ & M \\
\hline SUT0405.02 & 5.60 & 5.80 & $5.70 \mathrm{f}-\mathrm{i}$ & M \\
\hline SUT0405.17 & 5.10 & 5.30 & $5.20 \mathrm{ij}$ & M \\
\hline SUT0406.01 & 5.50 & 5.80 & $5.65 \mathrm{f}-\mathrm{j}$ & M \\
\hline SUT0406.09 & 5.60 & 5.70 & $5.65 \mathrm{f}-\mathrm{j}$ & M \\
\hline SUT0406.20 & 6.40 & 6.30 & $6.35 \mathrm{cde}$ & M \\
\hline SUT0412.01 & 5.80 & 5.80 & $5.80 \mathrm{e}-\mathrm{i}$ & M \\
\hline SUT0412.05 & 6.20 & 6.10 & $6.15 \mathrm{~d}-\mathrm{g}$ & M \\
\hline SUT0412.16 & 6.10 & 6.30 & $6.20 \mathrm{def}$ & M \\
\hline SUT0407.06 & 5.20 & 5.60 & $5.40 \mathrm{hij}$ & M \\
\hline SUT0409.03 & 5.50 & 5.60 & $5.55 \mathrm{~g}-\mathrm{j}$ & M \\
\hline
\end{tabular}

${ }^{1}$ Disease scores were based on the estimated percentage of infected leaf area: $1=$ no visible disease symptom; $2=1$ to $10 \%$ of the leaf area covered by lesions; $3=11$ to $20 \%$ of the leaf area covered by lesions; $4=21$ to $30 \%$ of the leaf area covered by lesions; $5=31$ to $40 \%$ of the leaf area covered by lesions; $6=41$ to $50 \%$ of the leaf area covered by lesions; $7=51$ to $60 \%$ of the leaf area covered by lesions; $8=61$ to $70 \%$ of the leaf area covered by lesions; $9=71$ to $80 \%$ of the leaf area covered by lesions; and $10=>80 \%$ of the leaf area covered by lesions from downy mildew infection.

${ }^{2}$ Data followed by the same letter in each column do not differ significantly $(p \leq 0.05)$ according to Duncan's multiple range test. ${ }^{3}$ Downy mildew resistance level based on lesion/disease severity scores as follows: 1.0 to $1.9=$ highly resistant (HR), 2.0 to $3.9=$ resistant $(\mathrm{R}), 4.0$ to $6.5=$ moderately resistant $(\mathrm{M}), 6.6$ to $9.0=$ susceptible $(\mathrm{S})$ and 9.1 to $10.0=$ highly susceptible (HS).

TABLE 4

Genetic analysis of disease severity under field conditions in 2011 and 2013.

\begin{tabular}{lcc}
\hline Genetic parameters & \multicolumn{2}{c}{ Years } \\
\cline { 2 - 3 } & 2011 & 2013 \\
\hline Phenotypic coefficient of variation & 31.94 & 33.31 \\
Genotypic coefficient of variation & 27.95 & 29.73 \\
Broad sense heritability & 76.57 & 79.69 \\
\hline
\end{tabular}

data were pooled over years to compare with the laboratory data. Variations in ranking between field and laboratory evaluations were observed, although the field results were generally in line with the data from the laboratory screening
(Table 5). All female parents were susceptible to the disease, with 'Black Queen' being the most susceptible cultivar under both laboratory and field disease assessments. Field and laboratory screening methods also classified 'NY88.0517.01' 
TABLE 5

Comparison of disease severity of Plasmopara viticola in detached leaf assay (laboratory) and natural field infection of eight grapevines genotypes and $18 \mathrm{~F}_{1}$ hybrids.

\begin{tabular}{|c|c|c|c|c|c|c|}
\hline \multirow[t]{2}{*}{ Genotypes } & \multicolumn{3}{|c|}{ Laboratory evaluation } & \multicolumn{3}{|c|}{ Field evaluation (2011 and 2013) } \\
\hline & Scores & $\operatorname{Rank}^{1}$ & Resistance levels & Scores & Rank & Resistance levels \\
\hline Black Queen & 4.83 & 26 & $\mathrm{~S}$ & 7.70 & 26 & $\mathrm{~S}$ \\
\hline Carolina Black Rose & 4.49 & 24 & $\mathrm{~S}$ & 7.50 & 25 & $\mathrm{~S}$ \\
\hline Early Muscat & 4.43 & 23 & $\mathrm{~S}$ & 6.80 & 23 & $\mathrm{~S}$ \\
\hline Italia & 4.60 & 25 & $\mathrm{~S}$ & 6.95 & 24 & $\mathrm{~S}$ \\
\hline Wilcox 321 & 3.01 & 15 & M & 3.30 & 1 & $\mathrm{R}$ \\
\hline NY88.0517.01 & 0.58 & 2 & $\mathrm{R}$ & 3.40 & 2 & $\mathrm{R}$ \\
\hline NY65.0550.04 & 0.83 & 5 & $\mathrm{R}$ & 3.65 & 4 & $\mathrm{R}$ \\
\hline NY65.0551.05 & 0.54 & 1 & $\mathrm{R}$ & 5.60 & 13 & M \\
\hline SUT0401.15 & 3.23 & 16 & $\mathrm{~S}$ & 5.55 & 11 & M \\
\hline SUT0401.32 & 0.87 & 6 & $\mathrm{R}$ & 5.35 & 8 & M \\
\hline SUT0401.33 & 0.70 & 3 & $\mathrm{R}$ & 5.05 & 5 & M \\
\hline SUT0410.20 & 2.63 & 14 & M & 6.00 & 18 & M \\
\hline SUT0410.31 & 3.73 & 18 & $\mathrm{~S}$ & 6.70 & 22 & $\mathrm{~S}$ \\
\hline SUT0403.09 & 0.70 & 3 & $\mathrm{R}$ & 3.40 & 2 & $\mathrm{R}$ \\
\hline SUT0404.08 & 1.00 & 8 & M & 5.20 & 6 & M \\
\hline SUT0404.11 & 0.98 & 7 & M & 5.35 & 8 & M \\
\hline SUT0405.02 & 1.10 & 9 & M & 5.70 & 16 & M \\
\hline SUT0405.17 & 3.29 & 17 & $\mathrm{~S}$ & 5.20 & 6 & M \\
\hline SUT0406.01 & 4.27 & 20 & $\mathrm{~S}$ & 5.65 & 14 & M \\
\hline SUT0406.09 & 4.40 & 22 & $\mathrm{~S}$ & 5.65 & 14 & M \\
\hline SUT0406.20 & 4.30 & 21 & $\mathrm{~S}$ & 6.35 & 21 & M \\
\hline SUT0412.01 & 3.90 & 19 & $\mathrm{~S}$ & 5.80 & 17 & M \\
\hline SUT0412.05 & 2.24 & 12 & M & 6.15 & 19 & M \\
\hline SUT0412.16 & 2.33 & 13 & M & 6.20 & 20 & M \\
\hline SUT0407.06 & 2.23 & 11 & M & 5.40 & 10 & M \\
\hline SUT0409.03 & 1.60 & 10 & M & 5.55 & 11 & M \\
\hline
\end{tabular}

${ }^{1}$ Disease severity scores were ranked from the lowest to the highest. The genotype ranked number 1 had the highest downy mildew resistance levels.

and 'NY65.0550.04' as resistant to downy mildew, suggesting their usefulness as parents for transferring downy mildew resistance gene(s). Among the $\mathrm{F}_{1}$ hybrids evaluated, 'SUT0403.09' ('Carolina Black Rose' x 'Wilcox 321') was resistant to downy mildew under both laboratory and field conditions. This hybrid had a higher fruit yield and quality than 'Wilcox 321', suggesting its potential as a breeding line for the future improvement of downy mildew resistance. It should be noted that 'NY88.0517.01', 'NY65.0550.04', 'SUT0401.33' and 'SUT0403.09' ranked among the first to fifth genotypes with the highest resistance levels under both laboratory and field conditions. Other than 'SUT0403.09', two hybrids, 'SUT0401.32' and 'SUT0401.33', were also classified as resistant under laboratory conditions, although their responses in the field were moderately resistant. The reasons for fluctuations in genotype ranking and responses to disease between the laboratory and field assessments may be due, in part, to differences in race composition and virulence of $P$. viticola populations in the field evaluations and those used in the laboratory screening. Such an effect of pathogen source on resistance ratings among Vitis accessions has been reported by Cadle-Davidson (2008), and could reflect genetic variation in $P$. viticola populations for overcoming race-specific resistance or minor quantitative resistance genes. In addition, some resistance mechanisms may lead to different resistance ratings under laboratory and field conditions. In the laboratory evaluation, the force of spray inoculation may overcome the physical barrier provided by hydrophobic leaf hairs on some genotypes. This will result in these leaves being more susceptible in the laboratory than under field conditions, where the leaf hairs provide protection under natural conditions (Kortekamp \& Zyprian, 1999; Cadle-Davidson, 2008). This may explain why 'Wilcox 321', which has dense leaf hairs (ca. two- to fourfold higher leaf hair density than 'NY88.0517.01' and 'NY65.0550.04'), was moderately resistant under laboratory conditions, but consistently exhibited a resistant phenotype in the field. The inconsistencies in results could also arise 
from the fact that a combination of true resistance and escape mechanisms existed in the field evaluations, whereas the escape mechanisms were avoided in the laboratory assay, where the conditions were optimal for downy mildew development.

When the relationship between laboratory and field evaluations was evaluated using Spearman's rank correlation, highly significant correlation $(p \leq 0.01)$ was observed between the laboratory and field results, with the Spearman's rank correlation coefficient of 0.73 indicating that the laboratory assessment was adequate at determining resistant and susceptible responses. These results are in agreement with previous work by Brown et al. (1999), who found significant correlations between sporulation ratings in the laboratory leaf disc procedure and field sporulation, chlorosis and necrosis ratings. Similarly, Eibach et al. (1989) reported that laboratory leaf disc evaluations significantly correlated with field evaluations. In this study, we used detached whole leaves and dispersed inoculum over a wider area of leaf tissues than what is used with leaf discs, which should allow for a more accurate evaluation of downy mildew resistance. The detached whole leaf screening technique was also reported to give consistent results with the whole plant screening technique among different $\mathrm{cv}$. Albariño clones (Boso et al., 2006). It should be noted that at least half of the grapevine genotypes classified as resistant by laboratory screening exhibited resistant responses in the field, and none of the susceptible genotypes under laboratory evaluation exhibited resistant responses in the field. These results confirm the efficiency of the laboratory detached leaf technique for screening the downy mildew resistance of grapevine genotypes. This laboratory screening assay allows for the rapid detection of resistant genotypes in only $8 \mathrm{~d}$. The assay also allows the evaluation of any plant, whether grown in the field or under controlled environment conditions. In addition, the non-destructive nature of this assay would be very useful for genetic analysis and breeding programmes. Using this laboratory screening assay, the susceptible seedlings could be discarded before being transplanted to the field, shortening the breeding process of the perennial grapevines for downy mildew resistance considerably, as well as reducing the cost of growing a large number of hybrids for field selection. However, once the resistant genotypes are identified, they should still be confirmed and evaluated for resistance durability under field conditions in different locations over several years.

Wild Vitis species are a potentially good source of resistance against $P$. viticola. A number of authors (Staudt \& Kassemeyer, 1995; Reisch \& Pratt, 1996; CadleDavidson, 2008; Jürges et al., 2009) indicated that some taxa of the genus Vitis, such as $V$. amurensis, $V$. aestivalis, $V$. berlandieri, $V$. candicans, $V$. cinerea, $V$. cordifolia, $V$. doniana, $V$. monticola, $V$. munsoniana, $V$. palmata, $V$. piasezkii, V. labrusca, $V$. rotundifolia, $V$. riparia, $V$. rupestris, $V$. shuttleworthii, $V$. tiliifolia, $V$. titanea, $V$. lincecumii and $V$. vulpina, show a wide range of resistance to downy mildew. Both resistant and susceptible accessions were found in most Vitis species evaluated (Cadle-Davidson, 2008). The highly resistant genotypes identified in our study also have wild Vitis species in their pedigrees, for example $V$. riparia ('Wilcox
321' and 'NY65.0550.04'), V. rupestris ('NY65.0550.04'), V. labrusca ('Wilcox 321' and 'NY65.0550.04'), and $V$. lincecumii ('NY65.0550.04'). The only hybrid with resistant responses at both laboratory and field levels identified in our study ('SUT0403.09') is derived from the 'Carolina Black Rose' $\times$ 'Wilcox 321' cross combination, which also has $V$. riparia and $V$. labrusca as some of its progenitors. In addition, 'SUT0403.09', 'Wilcox 321', 'NY88.0517.01' and 'NY65.0550.04' also provide field resistance to anthracnose in Thailand and are particularly valuable for breeding programmes when used to transfer multiple resistance genes into high yield and quality cultivars for sustainable grapevine production.

\section{CONCLUSIONS}

The detached leaf assay is efficient for downy mildew resistance screening under highly disease-prone conditions. The chip budding of the grapevine genotypes onto a rootstock did not affect the resistance response of the genotypes. Our study is the first to report the downy mildew resistance levels of 18 hybrids that were obtained from nine crosses between resistant lines and susceptible cultivars with high fruit quality. We identified three grapevine genotypes ('SUT0403.09', 'NY88.0517.01' and 'NY65.0550.04') that are resistant to downy mildew under both laboratory and field conditions. These genotypes will be very useful for future breeding programmes to obtain new cultivars with high resistance levels.

\section{LITERATURE CITED}

Agrios, G.N., 1997. Plant pathology. Academic Press, New York.

Barlass, M., Miller, R.M. \& Antcliff, A.J., 1986. Development of methods for screening grapevines for resistance to infection by downy mildew. I. Dual culture in vitro. Am. J. Enol. Vitic. 37, 61-66.

Bavaresco, L., Fregoni, M. \& Fraschini, P., 1992. Investigations on some physiological parameters involved in chlorosis occurrence in grafted grapevines. J. Plant Nutr. 15, 1791-1807.

Boso, S., Alonso-Villaverde, V., Gago, P., Santiago, J.L. \& Martínez, M.C., 2011. Susceptibility of 44 grapevine (Vitis vinifera L.) varieties to downy mildew in the field. Aust. J. Grape Wine Res. 17, 394-400.

Boso, S., Martínez, M.C., Unger, S. \& Kassemeyer, H.H., 2006. Evaluation of foliar resistance to downy mildew in different cv. Albariño clones. Vitis $45(1), 23-27$

Brown, M.V., Moore, J.N., Fenn, P. \& McNew, R.W., 1999. Comparison of leaf disk, greenhouse, and field screening procedures for evaluation of grape seedlings for downy mildew resistance. Hort. Sci. 34(2), 331-333.

CAB International, 2000. Crop protection compendium. CAB International, Wallingford.

Cadle-Davidson, L., 2008. Variation within and between Vitis spp. for foliar resistance to the downy mildew pathogen Plasmopara viticola. Plant Dis. 92, 1577-1584

Dabholkar, A.R., 1992. Elements of biometrical genetics. Concept, New Delhi.

Diana, V. \& Dejeu, L., 2011. Crown gall (Agrobacterium spp.) and grapevine. J. Hort. Forest. Biotechnol. 15(1), 130-138.

Eibach, R., Diehl, H. \& Alleweldt, G., 1989. Untersuchungen zur Vererbung von Resistenzeigenschaften bei Reben gegen Oidium tuckeri, Plasmopara viticola, und Botrytis cinerea. Vitis 28, 209-228. 
Gessler, C., Pertot, I. \& Perazzolli, M., 2011. Plasmopara viticola: A review of knowledge on downy mildew of grapevine and effective disease management. Phytopathol. Mediterr. 50, 3-44.

Jürges, G., Kassemeyer, H.-H., Dürrenberger, M., Düggelin, M. \& Nick, P., 2009. The mode of interaction between Vitis and Plasmopara viticola Berk. \& Curt. Ex de Bary depends on the host species. Plant Biol. (Stuttq.) 11(6), 886-898.

Kortekamp, A. \& Zyprian, E., 1999. Leaf hairs as a basic protective barrier against downy mildew of grape. J. Phytopathol. 147, 453-459.

Lafon, R. \& Clerjeau, M., 1988. Downy mildew. In: Pearson, H.M. \& Goheen, C. (eds). Compendium of grape diseases. APS Press, St. Paul, Minnesota. pp. $11-13$.

Levesque, R. \& SPSS Inc., 2006 ( $3^{\text {rd }}$ ed). SPSS programming and data management. SPSS Institute, Somers, New York.

Liu, S.M., Sykes, S.R. \& Clingeleffer, P.R., 2003. A method using leafed single-node cuttings to evaluate downy mildew resistance in grapevine. Vitis 42(4), 173-180.

Mahanil, S., 2007. Inheritance and cloning of candidate resistance gene analogs (RGAs) for downy mildew in grapevine (Vitis spp.). Ph.D. Thesis, Suranaree University of Technology, Nakhon Ratchasima, Thailand.

McCarthy, M.G. \& Cirami, R.M., 1990. The effect of rootstocks on the performance of Chardonnay from a nematode-infested Barossa Valley vineyard. Am. J. Enol. Vitic. 41, 126-130.

Nelson, B.D., Helms, T.C. \& Olson, M.A., 1991. Comparison of laboratory and field evaluations of resistance in soybean to Sclerotinia sclerotiorum. Plant Dis. 75, 662-665.

Nilnond, S., Chatbanyong, R. \& Jaemkerd, J., 2011. Effect of different rootstocks on growth, yield, fruit quality and wine quality of 'Chardonnay' grape on alkaline soil derived from limestone. Agric. Sci. J. 42(2)(Suppl), 229-232.

Okelola, F.S., Adebisi, M.A., Kehinde, O.B. \& Ajala, M.O., 2007. Genotypic and phenotypic variability for seed vigour traits and seed yield in West African rice (Oryza sativa L.) genotypes. J. Am. Sci. 3(3), 34-41.

Pavloušek, P., 2011. Evaluation of drought tolerance of new grapevine rootstock hybrids. J. Environ. Biol. 32, 543-549.

Pavloušek, P., 2012. Evaluation of foliar resistance of grapevine genetic resources to downy mildew (Plasmopara viticola). Acta univ. agric. et silvic. Mendel. Brun. 60(8), 191-198.
Poolsawat, O., Mahanil, S., Laosuwan, P., Wongkaew, S., Tharapreuksapong, A., Reisch, B.I. \& Tantasawat, P.A., 2013. Inheritance of downy mildew (Plasmopara viticola) and anthracnose (Sphaceloma ampelinum) resistance in grapevines. Gen. Mol. Res. 12(4), 6752-6761.

Poolsawat, O., Tharapreuksapong, A., Wongkaew, S., Chaowiset, W. \& Tantasawat, P., 2012. Laboratory and field evaluations of resistance to Sphaceloma ampelinum causing anthracnose in grapevine. Australasian Plant Pathol. 41, 263-269.

Reisch, B.I. \& Pratt, C., 1996. Fruit breeding, vol II. Vine and small fruit crops. Wiley, New York.

Reynolds, A.G. \& Wardle, D.A., 2001. Rootstock impact vine performance and fruit composition of grapes in British Columbia. Hort. Technol. 11(3), 419-427.

Satisha, J., Somkuwar, R.G., Sharma, J., Upadhyay, A.K. \& Adsule, P.G., 2010. Influence of rootstocks on growth yield and fruit composition of Thompson seedless grapes grown in the Pune region of India. S. Afr. J. Enol. Vitic. 31(1), 1-8

Schmid, J., Sopp, E., Ruhl, E.H. \& Hajdu, E., 1998. Breeding rootstock varieties with complete Phylloxera resistance. Acta Hort. 473, 131-135.

Sotolár, R., 2007. Comparison of grape seedlings population against downy mildew by using different provocation methods. Not. Bot. Hort. Agrobot. Cluj 35, 61-68.

Spearman, C., 1904. The proof and measurement of association between two things. Am. J. Psycho. 15, 72-101.

Staudt, G. \& Kassemeyer, H.H., 1995. Evaluation of downy mildew resistance in various accessions of wild Vitis species. Vitis 34(4), 225-228.

Stein, U., Heintz, C. \& Blaich, R., 1985. The in vitro examination of grapevines regarding resistance to powdery and downy mildew. J. Plant Dis. Protection 92, 355-369.

Striegler, R.K., Howell, G.S. \& Flore, J.A., 1993. Influence of rootstock on the response of Seyval grapevines to flooding stress. Am. J. Enol. Vitic. 44, 313-319.

Yun, H.K., Park, K.S., Rho, J.H., Kwack, Y.B., Jun, J.H., Jeong, S.T., Jang, H.I., Kim, S.H. \& Shin, Y.U., 2008. Table grape 'Jinok'. Hort. Sci. 43(7), 2222-2223.

Zamboni, A., Gatto, P., Cestaro, A., Pilati, S., Viola, R., Mattivi, F., Moser, C. \& Velasco, R., 2009. Grapevine cell early activation of specific responses to DIMEB, a resveratrol elicitor. BMC Genomics 10, 363. 